Elsevier Editorial System(tm) for Antiviral Research

Manuscript Draft

Manuscript Number: AVR-D-08-00053R3

Title: High-throughput screening using pseudotyped lentiviral particles: A strategy for the identification of HIV-1 inhibitors in a cell-based assay

Article Type: Research Paper

Section/Category:

Keywords: HIV; pseudotyped lentiviral particles; high-throughput screening; HTS; cocktail library; NNRTi.

Corresponding Author: Dr Jean-Michel Christophe Garcia, Ph-D

Corresponding Author's Institution: HKU-Pasteur Research Centre

First Author: Jean-Michel Christophe Garcia, Ph-D

Order of Authors: Jean-Michel Christophe Garcia, Ph-D; Anhui Gao; Pei-Lan He; Joyce Choi; Wei Tang; Roberto Bruzzone; Olivier Schwartz; Hugo Naya; Fa-Jun Nan; Jia Li; Ralf Altmeyer; JianPing Zuo

Manuscript Region of Origin: HONG KONG

Abstract: Two decades after its discovery the human immunodeficiency virus (HIV) is still spreading worldwide and killing millions. There are twenty-four drugs formally approved for HIV currently on the market, but major side effects as well as the emergence of HIV strains showing single or multiple resistances to current drug-therapy are causes for concern. Furthermore, these drugs target only 4 steps of the viral cycle, hence the urgent need for new drugs and also new targets. In order to tackle this problem, we have devised a cell based assay using lentiviral particles to look for post-entry inhibitors of HIV-1. We report here the assay development, validation as well as 
confirmation of the hits using both wild-type and drug-resistant HIV-1 viruses. The screening was performed on an original library, rich in natural compounds and pure molecules from Traditional Chinese Medicine pharmacopoeia, which had never been screened for anti-HIV activity. The identified hits belong to four chemical sub-families that appear to be all non nucleoside reverse transcriptase inhibitors. Secondary tests with live viruses showed that there was good agreement with pseudotyped particles, confirming the validity of this approach for high throughput drug screens. This assay will be a useful tool that can be easily adapted to screen for inhibitors of viral entry. 


\title{
High-throughput screening using pseudotyped lentiviral particles: A strategy for the identification of HIV-1 inhibitors in a cell-based assay
}

\author{
Jean-Michel Garcia ${ }^{a,}{ }^{,}$, Anhui Gao ${ }^{b}$, Pei-Lan $\mathrm{He}^{\mathrm{b}}$, Joyce Choi ${ }^{\mathrm{a}}$, \\ Wei Tang ${ }^{b}$, Roberto Bruzzone ${ }^{a}$, Olivier Schwartz ${ }^{c}$, Hugo Naya $^{d}$, \\ Fa-Jun Nan ${ }^{\mathrm{b},{ }^{*}}$, Jia $\mathrm{Li}^{\mathrm{b},{ }^{,}, \text {Ralf Altmeyer }}{ }^{\mathrm{a}, 1}$, Jian-Ping Zuo ${ }^{\mathrm{b},{ }^{*}}$
}

${ }^{a}$ HKU-Pasteur Research Centre, Hong Kong SAR, China

${ }^{b}$ Shanghai Institute of Materia Medica, Shanghai, China

'Virus \& Immunity Unit, Institut Pasteur, Paris, France

${ }^{\mathrm{d} I n s t i t u t}$ Pasteur de Montevideo, Uruguay

*Corresponding authors: Dr JM Garcia: jmgarcia@hkucc.hku.hk (HKU-Pasteur Research Centre Ltd, Dexter H.C. Man Building, 8 Sassoon Road, Pokfulam, Hong Kong SAR, China. Tel: (+852) 2816-81417, Fax: (+852) 2872-5782; Dr FJ Nan: fjnan@mail.shcnc.ac.cn \& Dr J Li: jli@mail.shcnc.ac.cn (National Center for Drug Screening, Shanghai Institute of Materia Medica, Shanghai Institutes for Biological Sciences, Chinese Academy of Sciences, 189 Guo Shou Jing Road, Shanghai 201203, China. Tel: (+86) 21-50801313; Fax: (+86) 21-50801552; Dr JP Zuo: jpzuo@mail.shcnc.ac.cn (Laboratory of Immunopharmacology, Shanghai Institute of Materia Medica, Chinese Academy of Sciences, 555 Zuchongzhi Road, Zhangjiang Hi-Tech Park, Shanghai 201203, China. Tel/fax: (+86) 21-50806701).

${ }^{1}$ Present address: CombinatoRx, 11 Biopolis Way, Helios \#08-05/06, Singapore 138667. 
Abbreviations:

3TC: Lamivudine

AZT: Zidovudine

BSL: Biosafety Level

CPRG : Chlorophenol Red- $\beta-D-G a l a c t o p y r a n o s i d e$

CPE: Cytopathic effect.

d4T: Stavudine

ddl: Didanosine

DMSO: Dimethyl Sulfoxide

FCS: Fetal Calf Serum

GFP: Green Fluorescent Protein

HIV: Human Immunodeficiency Virus

Luc: Luciferase

MDR: Multi-Drug Resistant

MTT: 3-(4,5-Dimethylthiazol-2-yl)-2,5-diphenyl tetrazolium bromide

NNRTi: Non Nucleoside Reverse Transcriptase Inhibitor

NVP: Nevirapine

PDB: Protein Data Bank

SFV: Semliki Forest Virus

VSV-G: Protein G of the Vesicular Stomatitis Virus 


\section{Abstract}

Two decades after its discovery the human immunodeficiency virus (HIV) is still spreading worldwide and killing millions. There are twenty-four drugs formally approved for HIV currently on the market, but major side effects as well as the emergence of HIV strains showing single or multiple resistances to current drug-therapy are causes for concern. Furthermore, these drugs target only 4 steps of the viral cycle, hence the urgent need for new drugs and also new targets. In order to tackle this problem, we have devised a cell based assay using lentiviral particles to look for post-entry inhibitors of HIV-1. We report here the assay development, validation as well as confirmation of the hits using both wild-type and drug-resistant HIV-1 viruses. The screening was performed on an original library, rich in natural compounds and pure molecules from Traditional Chinese Medicine pharmacopoeia, which had never been screened for anti-HIV activity. The identified hits belong to four chemical sub-families that appear to be all non nucleoside reverse transcriptase inhibitors. Secondary tests with live viruses showed that there was good agreement with pseudotyped particles, confirming the validity of this approach for high throughput drug screens. This assay will be a useful tool that can be easily adapted to screen for inhibitors of viral entry.

Keywords: HIV; pseudotyped lentiviral particles; high-throughput screening; HTS; cocktail library; NNRTi; 


\section{Introduction}

More than two decades after the identification of Human Immunodeficiency Virus (HIV) as the causative agent of AIDS, the disease remains a huge concern for global public health. In 2007 it was estimated that 33.2 million people worldwide were living with HIV, 2.5 millions became newly infected and 2.1 millions of patients died of AIDS (UNAIDS/WHO, 2007). Although the HIV prevalence rate is still low, South-East Asia is one of the regions where the HIVIAIDS epidemic is most rapidly growing. AIDS is considered a serious threat to public health and safety in China, and also a strategic issue for social stability, economic growth, national prosperity and security. Furthermore, an increasing portion of patients with HIV cannot use currently approved anti-HIV drugs due to the adverse effects and because of the emergence of HIV strains showing single or multiple resistances to current drug-therapy (Yeni, 2006).

To date, antivirals are the only therapeutic option to manage HIV as the recently publicized failure of a Phase II vaccine trial pushes back the prospects of an effective prophylactic vaccine (Cohen, 2007a, 2007b). Despite 29 commercially available drugs (Flexner, 2008), these molecules belong to only seven therapeutic classes and target only 1 cellular and 4 viral proteins: the cellular co-receptor CCR5 (Maraviroc), the surface envelope glycoprotein gp160 (the peptide Enfuvirtide), reverse transcriptase (10 nucleoside and 3 nucleotide analogs; 3 non-nucleoside analogs), protease (10 peptidomimetic) and integrase (Raltegravir). Due to increasing resistance to existing therapies, HIV drug development is searching for new agents in classes that do not share cross-resistance, as well as for new classes of drugs that would either not be affected by such resistance or would act on new targets (Sension, 2007). Because of resistance, available drugs are no longer used as monotherapy (Pillay et al., 2000) but, rather, in a combination of drugs targeting different steps in the viral life cycle, termed highly active 
antiretroviral therapy (HAART).

Altogether, the emergence of drug resistant HIV strains, the important side effects of current drugs and their high cost underscore the importance for the developments of new treatments to fight the AIDS pandemic. The mechanism of HIV replication involves a complex interplay between virus and host cells, from cell attachment to release of newly assembled virions (Sorin and Kalpana, 2006). Therefore, every single step is potentially a potential target for drug discovery (Bennasser et al. 2007; Esté and Telenti, 2007; Faustino et al. 2007; Liu et al. 2007; Salzwedel et al. 2007; Zeinalipour-Loizidou et al. 2007).

We have taken advantage of high-throughput screening (HTS) technology using a cell-based assay to look for new inhibitors of post-entry events in HIV infection. Identification of HIV antiviral molecules from natural products has been pursued with success and has been extensively reviewed by De Clercq (2000). The screening was performed on an original library, rich in natural compounds and pure molecules from the Traditional Chinese Medicine (TCM) pharmacopoeia, which had never been screened for anti-HIV activity. Here, we describe an efficient and cost-effective antiviral screening system that utilizes pseudotyped viruses for primary antiretroviral screening. 


\section{Materials and methods}

\subsection{Cells}

MT4 cells were cultured in RPMI 1640 with Glutamax (Invitrogen) supplemented with 10\% Fetal Calf Serum (FCS) (Sigma) and penicillin-streptomycin (100 IU/ml each, Sigma). HeLa cells (P4 and P4C5 clones; Maréchal et al., 1998) were maintained in Dulbecco's modified Eagle's medium (DMEM) with Glutamax supplemented with 10\% FCS and penicillin-streptomycin. P4 and P4C5 HeLa cells are CD4+ carrying an HIV long terminal repeat (LTR) lacZ reporter cassette; they express either CXCR4 (P4 cells), or CXCR4 and CCR5 (P4C5 cells) surface co-receptors for the envelope glycoprotein gp160.

\subsection{Design and production of pseudotyped virus}

The pseudotyped virus was engineered from two plasmids, one coding for envelope, and the second for backbone and reporter gene. The glycoprotein $G$ from Vesicular Stomatitis Virus (VSV-G) was selected as the envelope protein because it allows the infection of a very wide range of cell types from a variety of organisms (Burns et al., 1993). VSV-G interacts with a phospholipid component of the cell surface membrane and mediates viral entry by membrane fusion (Mastromarino et al., 1987). Furthermore, VSV-G pseudotyped viruses have already been shown to provide high titers (Burns et al., 1993). Because the target of our screening was HIV-1 replication, the polyprotein sequence from proviral vector pNL4.3-Luc E', with env deleted, was used as the backbone and engineered to express the firefly luciferase gene (Connor et al., 1995), which was selected over fluorescent reporters for the larger working range (4-log) and greater sensitivity it allows (Olesen et al., 2000; data not shown). These virions are valuable reagents for antiviral screening since they allow a reduction in viral RNA replication to be measured by direct enzymatic quantification of luciferase in the cell lysate using a 
simple add-and-read type of cell-based assay.

Production of these pseudotyped viruses with a single infectious cycle was based on a previously published design (Naldini et al., 1996), by co-transfecting HEK293T cells ("producer cells") with a plasmid expressing the envelope protein (VSV-G) and a plasmid containing the modified proviral genome of HIV. In the producer cells only the transcript from the proviral plasmid was packaged into the capsid due to the presence of the packaging signal in the plasmid sequence. During the budding process, capsids were enveloped by the VSV-G proteins expressed on the cell surface prior to their release into the medium. A similar procedure was applied to produce two other pseudoptypes: a first one in which the VSV-G gene is replaced by the HIV envelope HxB2; and a second one in which the Enhanced Green Fluorescent Protein (GFP) was used as the reporter gene instead of luciferase.

\subsection{Compounds and library}

3'-Azido-3'-deoxythymidine (AZT) was purchased from Sigma. Compounds were provided by the National Centre for Drug Screening (NCDS, Shanghai, China) associated with the Shanghai Institute of Materia Medica (SIMM). This national library is composed of more than 100000 samples, $70 \%$ of which are pure and chemically defined compounds, whereas the remaining $30 \%$ are extracts from either micro-organisms or TCM formulation. $10 \%$ of the pure compounds are from natural sources and 2-3000 are pure compounds from TCM, the largest such collection in the world. The origin of the pure synthetic compounds is either from commercial libraries (ensuring a diversity of templates) or from Chinese chemical laboratories. All pure compounds respect Lipinski rules for drugability. Together, several hundred scaffolds are represented, covering a large part of the chemical space. In this project we decided to screen a sub-library of 48000 pure compounds that was already formatted in orthogonal cocktail. 


\subsection{Orthogonal cocktail strategy}

Compound library samples were orthogonally pooled as mixtures of 10 compounds per well at $2 \mu \mathrm{g} / \mathrm{mL}$ each, with duplicate representation for each compound. This bidirectional orthogonal pooling strategy allows for greater screening efficiency and throughput for large compound libraries. The pooling was prepared as follows. One hundred plates (96-wells), containing a single compound/well ("source plates"), were laid out in a $10 \times 10$ grid. Orthogonal cocktails were then made by mixing into one well of the "cocktail plate" each compound from the same well of 10 "source plates" (Figure 1). Each compound was represented twice in 20 "cocktail plates", each time with 9 different sister compounds. Therefore, because the mixture were made orthogonally, each compound was present in two orthogonal cocktail wells and, conversely, two orthogonal cocktail wells have only one compound in common. Assuming that the chance to encounter two positive compounds within the same cocktail is negligible, it is postulated that a high activity measured in two orthogonal wells is most likely caused by the one compound in common.

\subsection{Primary screening}

Test compounds were prepared from initial dimethyl sulfoxide (DMSO) stocks and plated as described above, 80 cocktails per plate. Low passage HeLa-P4 cells were then trypsinized, counted and seeded at a final concentration of $10^{4}$ cells/well. Plates were left 1 hour at room temperature before being placed overnight in a $\mathrm{CO}_{2}$ incubator in order to avoid the edge effect (Lundholt et al., 2003). The following day, samples and controls (AZT) were then added with an automatic liquid handler (FX from Beckman-Coulter). Finally, the pseudotyped virus, thawed and diluted immediately prior to use in cell culture medium, was added under a BSL-2 hood using Hydra (Thermo Fisher Scientific). The final concentration of DMSO in all wells was maintained at $2 \%$. The plates were incubated at $37^{\circ} \mathrm{C}$ in a humidified $\mathrm{CO}_{2}$ incubator for 48 hours. Steady-glow substrate (Promega) was added directly to 
each well with the FX automatic liquid handler and cell lysis was allowed to proceed in the dark for 20 minutes. Luciferase activity was measured using the Envision microplate luminometer (Perkin Elmer).

\subsection{Primary cytotoxicity screening}

The cytotoxicity of "active" compounds identified during the primary screening was evaluated by MTT (3-(4,5-Dimethylthiazol-2-yl)-2,5-diphenyltetrazolium bromide) assay at the end of the incubation period (Mosmann, 1983). Briefly, HeLa-P4 cells $\left(10^{4}\right.$ cells/well, $\left.50 \mu \mathrm{L}\right)$ were plated in 96-well microtiter plates and incubated for 18 hours at $37^{\circ} \mathrm{C}$ (humidified atmosphere, $5 \% \mathrm{CO}_{2}$ ), followed by a second incubation for 48 hours in the presence of the test compounds. MTT (20 $\mu \mathrm{l}$ at $5 \mathrm{mg} / \mathrm{mL})$ was added to each well and incubated for 3 hours at $37^{\circ} \mathrm{C}$ after which medium was replaced by $100 \mu \mathrm{L}$ of DMSO. The plates were placed on a shaker for $10 \mathrm{~min}$ at room temperature and the $\mathrm{OD}_{550}$ measured using a SpectraMAX340 microplate reader (Molecular Devices) with a reference wavelength at $690 \mathrm{~nm}$.

\subsection{Time of addition study}

MT4 cells were seeded at $10^{4}$ cells/well in $50 \mu \mathrm{L}$ of RPMI 1640 supplemented with Glutamax and 10\% FCS, left for rest one hour at room temperature to avoid the edge effect and placed overnight into incubator at $37^{\circ} \mathrm{C}$. The following day, cells were infected with $50 \mu \mathrm{L}$ of pseudoparticles; each compound as well as AZT was added at a final concentration of $4 \mu \mathrm{M}$ at different time points and up to 30 hours, with $\mathrm{t}=0$ defined as the time of pseudoparticle addition. Sample solutions were kept at $4^{\circ} \mathrm{C}$. At 48 hours post infection, cells were lysed with $100 \mu \mathrm{L}$ of steady glow luciferase substrate and bioluminescence was measured after further 20 min incubation within the microbeta plate reader (Perkin Elmer). 


\subsection{In-Silico docking}

In silico docking of selected hits in the reverse transcriptase structure crystallized with the NNRTI Nevirapine (PDB accession number 1FKP) was performed with the program Arguslab 4.0.1 from Mark Thompson and Planaria Software LLC (website). Docking parameters used were as follows: ArgusDock for the docking engine; Binding site Bounding Box settings to cover the entire reverse transcriptase protein (grid resolution 0.4 Ang.); Calculation type: Dock; Ligand: flexible.

\subsection{HIV-1 virus infection}

The production and use of wild-type (WT) and mutant HIV have been previously described (Petit et al., 2001). The various drug-resistant strains were derived from NL4.3, a CXCR4-tropic HIV strain (Moore et al., 2004), and were a kind gift of Fabrizio Mammano (Institut Pasteur, Paris) and Elisabeth Dam (INSERM U552, Hôpital Bichat, Paris): NL4.3XCS MDR 151, which is resistant to various nucleoside analogues (Zidovudine (AZT), Stavudine (d4T), Didanosine (ddl)); NL4.3XCS 41-215, which is AZT resistant; NL4.3XCS M184V, which is Lamivudine (3TC) resistant; NL4.3XCS K103N, which is Nevirapine (NVP) resistant; and NL4.3XCS 188L-190A, which is highly resistant to NVP (de la Carrière et al., 1999).

For single-cycle HIV infection experiments, P4 or P4C5 cells carrying an HIV long terminal repeat (LTR) lacZ reporter cassette $\left(1.5 \times 10^{4}\right.$ cells/well, in triplicates), were pre-incubated 30 minutes with the indicated drugs, and then exposed to the different virus stocks. Viral input, quantified as ng of p24 (Sol-Foulon et al., 2007), was either $1 \mathrm{ng}$ or $5 \mathrm{ng}$ of p24/well (equivalent to an MOI of $\sim 0.02$ or MOI $\sim 0.1$ respectively, see following section 2.10 for detail on MOI calculation). Cells were briefly centrifuged (5 minutes at $1200 \mathrm{rpm}$ ), maintained in the presence of drugs for 48 hours and then ß-galactosidase activity was measured in a colorimetric CPRG assay at an $\mathrm{OD}_{540}$ (Eustice et al., 1991). 


\subsection{Calculation of the MOI}

Titration of HIV was performed as described (Schwartz et al., 1995). Briefly, virus stocks were assessed for Gag p24 concentration using a commercial antigen capture ELISA (Du Pont de Nemours-NEN, HIV-1 p24 Core Profile ELISA), according to the manufacturer's instructions. Infectivity of viral supernatants was determined using P4 cells. These HeLa-CD4 cells carry the bacterial LacZ gene under the control of the HIV-1 LTR, and cytoplasmic accumulation of $ß$-galactosidase is strictly dependent on the presence of Tat. One day before infection, $1.2 \times 10^{5}$ cells/well were seeded in a 24 -well plate. The following day, the medium was replaced with $500 \mu \mathrm{l}$ of diluted virus stock (serial dilutions in culture medium from 100 to $0.1 \mu \mathrm{l}$ ) in the presence of 20 $\mu \mathrm{g} / \mathrm{ml}$ of DEAE-Dextran. After 3 hours of incubation with the viral samples, 1 $\mathrm{ml}$ of fresh medium was added. After 24 -hour incubation at $37^{\circ} \mathrm{C}$, cells were fixed and $ß$-galactosidase activity was revealed with 5-bromo-4-chloro-3-indoyl-ß-D-galactopyranoside (X-Gal). Blue cells foci were scored under a binocular microscope. Experiments were performed in triplicate or in duplicate, and variations for each viral dilution were less than $10 \%$. A background level of 5 to 15 blue cells was detected in wells of uninfected cells and was subtracted from the number of blue cells scored for experimental points. This assay was reproducible and generated linear values when serial virus dilutions were used. We generally obtain 500-1000 
blue foci per ng of p24. Therefore, in 96 -well plates seeded with $1.5 \times 10^{4}$ cells per well, infection with 1 and 5 ng of p24 per well corresponds to an MOl of 0.02 and 0.1 , respectively.

\subsection{Data analysis}

Assay quality and robustness were determined during the optimization as well as during the screening by calculation of the statistical parameters Z (and Z') introduced by Zhang (Zhang et al., 1999). To determine the effects of the compounds in the assay, data were compared to a cut-off value defined as mean of the control and inactive compound (all except outliners) minus twice their standard deviation using homemade macros in Excel (Microsoft). Because of the orthogonal cocktail strategy, we assessed for each well the concordance of inhibition (below the set cut-off limit) in paired "cocktail plates". Concordant wells represent, therefore, a "positive" that needs to be subsequently confirmed as individual compound to become an "active" molecule.

Estimates for $I_{50}$ were obtained using "drc" package (Ritz \& Streibig, 2005) for "R" (http://www.R-project.org). Weibull and Logistic regression with 3 or 4 parameters (W3, W4, L3 and L4) were adjusted, and a lack-of-fit test performed, comparing the non-linear regression model to a more general one-way ANOVA model. Non-significant values $(p>0.01)$ for this test suggest the model provide comparable performance to the one-way ANOVA. In the next step comparisons between nested models were also conducted via ANOVA, with significant values $(p<0.01)$ pointing evidence toward more complex models. Finally, all adjusted curves were visually inspected for ultimate decision when statistics test do not provide sufficient evidence to favor any model. 


\section{Results}

\subsection{Assay development and optimization}

In this report, we describe the development, validation and use of pseudotyped lentiviral particles for in vitro cell based screening of antiviral compounds. Several experimental parameters were found to affect the readout and were optimized including cell type and number, concentrations of DMSO and pseudoparticles, timing of each step (reagent additions, infection/incubation, endpoint measurement), different types of luciferase substrates as well as protocol of compound delivery (Figure 2).

\subsection{Assay automation and validation for HTS}

While the development and optimization of the assay were done manually, screening of large number of compounds requires an automated process. During the validation step of the assay on the automated platform we observed an unexpectedly high coefficient of variation between replicates. This variation could be attributed mainly to the step of adding $2 \mu \mathrm{L}$ of compounds in DMSO to $98 \mu \mathrm{L}$ of medium. To optimize this step we tested the accuracy of sample delivery with a DMSO solution containing 4-nitro-phenylamine by direct reading of absorbance $\left(\lambda_{\max }=412 \mathrm{~nm}\right)$. A significant reduction of the coefficient of variation from $8 \%$ to below $2 \%$ was achieved by including in the protocol an additional $20 \mu \mathrm{L}$ washing step to ensure proper recover of the drug from the tip while mixing the sample (data not shown). As the compounds were formatted in 80 cocktails per plate in columns 2 to 11 , controls (DMSO only and AZT in DMSO) were added for the assay to each side (columns 1 and 12) with 96-tips head filled only with these two columns. Therefore, we also checked that this procedure did not affect the reproducibility of dispensing samples (data not shown). The assay was then validated on a representative subset of the library (800 compounds) tested three times. The statistical parameters of the assay indicated that both quality $\left(Z^{\prime}=0.72, Z=0.60\right)$ as 
well as reproducibility given by the intra-plate and inter-plates coefficients of variation $\left(\mathrm{CV}_{\text {intra }}=2.1 \%, \mathrm{CV}_{\text {inter }}=3.4 \%\right)$ were adequate.

\subsection{Primary screening}

We have used this assay for the screening of a library of 48000 pure compounds, formatted in orthogonal cocktails. As illustrated in Figure 3 for one of the six batches of 20 plates of orthogonal cocktails, most compounds did not show any inhibitory activity. A sample was considered positive for inhibitory activity when both values from $\mathrm{Y}$ - and $\mathrm{X}$-plates fell below the cut-off (defined as the average $(\mathrm{m})$ minus two standard deviations (SD): m-2SD). A total of 63 molecules were confirmed in singlet and identified as active, 32 of which were excluded as toxic by the MTT assay. Therefore, a total of 31 compounds, which showed no cytotoxicity at concentrations as high as $2 \mu \mathrm{g} / \mathrm{ml}$ (range $4-9 \mu \mathrm{M}$ ), represent primary hits (hit rate: $0.06 \%$ ). Given the inhibitory effect measured for these molecules (Supplementary Materials, Figure S1), this hit rate is comparable to that observed by Noah et al. (2007) when they used a cutoff threshold of $50 \%$ inhibition.

\subsection{Analysis of the hits}

To exclude that the observed inhibition was due to a trivial interference with the entry step mediated by VSV-G envelope protein, or with the enzymatic activity of the luciferase reporter gene, we used the same lentiviral backbone pseudotyped with either HxB2 envelope from HIV or containing GFP as the reporter gene, respectively. These two swaps (HIV-HxB2 for VSV-G and GFP for luciferase) did not modify the inhibitory profile, indicating that the hits affected at least one post-entry step of the HIV life cycle up to the translation of reporter gene. Furthermore, these hits were not active against Semliki Forest Virus (SFV, an alphavirus), thus suggesting some degree of specificity (Figure 4). The calculated $I_{50}$ of the drugs in these assays with HIV-HxB2-HIV(Luc), VSV-G-HIV(Luc) and 
VSV-G-HIV(GFP) was generally in the sub-micromolar range (Table 2). The apparent higher $\mathrm{IC}_{50}$ measured with live wild type virus compared with HxB2-HIV(Luc) pseudovirus is due to the fact that the virus has several rounds of infection/replication, whereas the replication-deficient pseudoparticle, by definition, can only infect once. Furthermore, in the live virus assay, fusion between infected and non infected cells can be observed; this favors the passage of tat protein from one cell to the other leading to LTR transactivation on non infected cells. This exponential mechanism could explain why a higher drug concentration is required with live virus. Finally, in order to gain some insight into the specific step that was targeted, we performed time of addition experiments. Our results show that the time course of neutralization followed that induced by AZT, suggesting either an inhibition of the reverse transcriptase or of a concomitant step (Figure 5).

We next examined the general structure of the hits and identified four sub-families derived from a common template that comprises a first aryl with preferentially electron-withdrawal groups, attached via a linker of variable length and flexibility to another aryl bearing preferentially electron-rich groups (Figure 6). For the first family, the linker can be described as a heterocycle (mainly, but not only, tetrazole groups) substituted with an electron-rich group (e.g. thioacetanilide) followed by a hydrogen-bond donor in beta. For the second family, the linker is derived from the N'-ethyl thio-urea moiety. The third family can be described as a polycyclic aromatic group (chiefly aryl/heterocycle) linked with an electron-rich group to another frequently substituted aryl group. The fourth family combines the characteristics of all other molecules with no additional specific features. The chemical structure analysis of the inactive compounds showed that both aromatic moieties are required for the activity but the structures are not close enough to infer structure-activity-relationships, as in each case more than one potential pharmacophore is different. Nevertheless, this information will be important for further pharmacochemical development of the lead compounds (Supplementary Materials, Figure S1). 


\subsection{In-silico docking}

The general template of all identified hits, with peripheral aromatic rings, showed some resemblance to the structure of known non nucleoside reverse transcriptase inhibitors (NNRTI) (Figure 6). In order to test the hypothesis that reverse transcriptase was indeed the target, we performed in silico docking of six compounds representative of the four chemical families in the reverse transcriptase structure crystallized with the NNRTI Nevirapine (PDB accession number 1FKP). Our data show that they all dock to the same binding pocket as nevirapine (Figure 7), whereas all other drugs tested for comparison (including antivirals such as Stavudine, Saquinivir, Acyclovir and Oseltamivir) did not (data not shown). Most type I compounds bear a tetrazol group that is related to the structure of 5 CITEP (1-(5-chloroindol-3-yl)-3-hydroxy-3-(2H-tetrazol- 5-yl)-propenone) (Goldgur et al., 1999), an inhibitor of the integrase, which was another potential target of our screen. To evaluate this possibility, we performed in silico docking of known integrase inhibitors to the structure of integrase found in Protein Data Bank (1BL3 and $1 E X Q)$. However, this attempt was not successful, thereby preventing further analysis with our hits.

\subsection{Inhibitory activity on wild-type and drug-resistant mutant viruses}

To demonstrate that the screening assay with pseudotyped lentiviruses was able to identify bona fide inhibitors of HIV replication, we tested the six most potent hits on different HIV strains. Because chemical structures analysis as well as reverse in silico docking suggested that the compounds are non-nucleoside reverse transcriptase inhibitors, they were tested against wild type HIV virus (NL4.3 strain) as well as against mutants resistant to either nucleoside inhibitors (AZT, d4T, ddl, 3TC) or non nucleoside inhibitors (NVP). 
Virus infection was measured in the presence of drugs tested at three different concentrations ( $5 \mu \mathrm{M}, 1 \mu \mathrm{M}$ and $0.1 \mu \mathrm{M})$ and compared to control values obtained with either non infected cells or cells infected without drugs (Figure 8). Depending on the viral strain tested, appropriate control drugs were also added to the experiment. As expected, infection of cells with the wild type virus resulted in a robust signal that was blocked by the drugs tested in a dose-dependent fashion (Figure 8A). The mutant viruses showed a different sensitivity to our drugs. Thus, all compound tested displayed anti-HIV activity against strains resistant to nucleosidic antivirals, whereas they were by-and-large ineffective against NVP-resistant viruses (Figure $8 \mathrm{E}-\mathrm{F}$ ). For most of these combinations, estimates for $\mathrm{IC}_{50}$ (Table 1 and supplementary material $\mathrm{S} 1$ respectively for viral input of MOI 0.02 and $\mathrm{MOI} 0.1$ ) were obtained using the freely downloadable package "drc" for "R". An illustration of curve fitting with the L4 model is shown for AZT in the Supplementary Material (Figure S2). Of note, NC83040 was the most potent against wild-type and NRTI-resistant strains, and NC87463 exhibited a partial inhibition on the $\mathrm{K} 103 \mathrm{~N}$ nevirapine resistant strain. All IC 50 ranged between nanomolar to low micromolar, depending on the viral strain used. None of the tested hits showed a significant inhibition of the highly NVP-resistant strain and, therefore, no $\mathrm{IC}_{50}$ could be derived.

\section{Discussion}

Pseudotyped particles contain the envelope protein from one virus and the core from another and mimic some behavior of the wild type viruses (Ma et al., 1999). They have been utilized as convenient tools for several applications. If the heterologous envelope is the focus of the study, on the one hand, the involvement of the surface glycoprotein can be investigated, for example studies on the entry mechanism of Ebola (Wool-Lewis \& Bates, 1998), Marburg (Chan et al., 2001) or hepatitis C (Codran et al., 2006) viruses, the development of sero-diagnostic tests 
for avian influenza (Nefkens et al., 2007) or SARS (Fukushi et al., 2006), vaccination (Bukreyev et al., 2006) or the evaluation of entry inhibitors (Chan et al. 2006). If the properties of the particles' core are the focus of the study, on the other hand, VSV-G envelope has been commonly used for its wide tropism, with well known applications to gene therapy (Baum et al., 2006; Kim et al., 2000). Thus, a pseudotype-based assay would permit high-throughput screening in a BSL-2 contained platform of new drugs inhibiting entry of pathogens that would otherwise require a BSL-3/4 facility. The validation of this assay is the first necessary step in this direction.

In this study, we have used lentiviral particles pseudotyped with VSV-G to screen the library for compounds that would target the post-entry events, i.e. in this case lentiviral replication. The present results have, therefore a dual output, validating the pseudotype strategy for high-throughput screening in drug discovery and identifying new molecules with antiviral activity against HIV-1. The results obtained with particles pseudotyped with different viral glycoproteins will be described in a separate paper after completion of the relevant screenings. While this manuscript was under revision, an article in Chinese describing a similar pseudoparticle-based assay appeared in PubMed (Cao and Guo, 2008). Their work was on a much smaller scale (only 500 compounds tested), their hits were effective in the micromolar range and the specific target was not mentioned.

The assay is robust, flexible and compatible with medium to high throughput. We have validated it for inhibitors of HIV replication and identified novel hits belonging to four chemical sub-families that appear to be all non nucleoside reverse transcriptase inhibitors (NNRTi). Confirmatory tests with live viruses showed that there was good agreement with pseudotyped particles. In addition, we took advantage of naturally occurring viral mutations associated with drug resistance and observed that the efficacy of our hits matched the behavior expected for the therapeutic class they belong to, viz. NNRTi. 
Screening large libraries can be very cumbersome and expensive. The first solution to this problem was to mix the compounds to be tested in pools (usually of 10 molecules). Despite the evident advantage of compound pooling, the results obtained from testing such mixtures necessitate complex deconvolution analysis. An elegant alternative method consists of mixing the compounds according to a matrix-like layout in an orthogonal cocktail, thereby facilitating the identification of the active compounds. The two additional benefits of this strategy are to increase the robustness of the assay by testing each compound in duplicate while considerably reducing the number of plates in each screen. Although a small scale screening of single molecules could have been performed in parallel, we reasoned that the most potent compound would be identified also in a cocktail mix.

Nevertheless, we should mention an intrinsic limitation of the orthogonal cocktail screen is that if several compounds in one well are either active or toxic, it multiplies the pair wise possibilities to trace back and identify the active one. For example, during the screening of one batch, 3 pair-wise $X Y$ plates showed a reduction of luciferase signal in same well F8. In order to investigate which compound(s) was (were) responsible for the inhibitory effect, 9 compounds (corresponding to $3^{2}$ ) needed to be tested individually. In this case, only one molecule, NC85497, showed true inhibition, whereas 2 were toxic and the remaining 6 did not show any effect (Supplementary Material, Figure S3). Fortunately such occurrence is relatively rare (owing to the limitation of the cocktail to 10 compounds) and all together this strategy still reduces the overall number of wells to be tested, compared to single-compound screening, and therefore cost and time.

The robustness and sensitivity of this cell-based assay was due to two main factors: the cell line used and the selection of the reporter gene. The choice of a cell type is a critical parameter for assay robustness, biological relevance and reproducibility. 
HeLa cells have been routinely used for HIV studies (Clavel \& Charneau, 1994; Morizono \& Harada, 1998; Watanabe et al., 2000) and have also the advantage to exhibit a relatively high tolerance to DMSO (up to $5 \%$ in our assay conditions). An appropriate readout was another crucial component. Luminescent reporter genes provide highly sensitive, quantitative detection in simple, rapid assay formats. The sensitivity of these chemoluminescent detection methodologies typically is several orders of magnitude greater than that of conventional colorimetric or fluorometric detection methods (Olesen et al. 2000).

Despite the fact that the cell-based assay was designed to identify not only new drugs but also new targets for HIV, all our hits seems to belong to the well-studied class of NNRTIs. When comparing their chemical structures to other NNRTIs described in the literature, compounds from the first family are close to tetrazole thioacetanilide derivatives published after completion of our screening (Muraglia et al., 2006). These compounds present very good antiviral activity ( $\mathrm{IC}_{50}$ at 3-9 nM) even against K103N mutant, the most frequently occurring NNRTi drug-resistant strains (Soriano \& de Mendoza, 2002), as well as an excellent pharmacokinetic profile in rat (Muraglia et al., 2006). These results illustrate the good quality of the hits' chemical structures. Another important output of the screening is the fact that the other three sub-families of the hits present an overall similar structure but yet a diverse chemical template. That will help the future pharmacochemical development of the compounds, as we can use novel templates with the help of more extensive in silico modeling and structure-activity relationship from the screening results (viz. chemically related compounds with lower or no activity or higher cytotoxicity) as blueprints to derive series through chemical modifications of the chosen lead compounds. Although all steps of the lentiviral reporter system should be equally exposed to our panel of compounds, it is notable that all the compounds with antiviral activity found were inhibitors of reverse transcriptase. This may simply reflect the compounds present in the library. A systematic bias towards inhibitors of reverse transcriptase (rather than, for example inhibitors of 
integrase) is however unlikely although this can only be formally excluded in future screens which include known integrase inhibitors in the chemical library.

In summary, we have developed, optimized and validated a high throughout, cell-based assay using pseudotype particles. This assay was successfully used for the screening of HIV-1 inhibitors and can be easily adapted to screen for entry inhibitors using a different surface glycoprotein and an appropriate cell line.

\section{Acknowledgements}

The authors are grateful to Dr Pierre Charneau (Institut Pasteur) for providing the pNL4.3 Luc E' plasmid, to Drs Fabrizio Mammano (Institut Pasteur) and Elisabeth Dam (INSERM U552, Hôpital Bichat, Paris) for the kind gift of plasmids expressing WT and drug-resistant viruses and to Françoise Porrot for testing the effects of the compounds on replicating HIV. We thank Prof. Paul Vanhoutte and Madeline Yap (Biopharmaceutical Development Centre, HKU) for continuous encouragement and advice throughout the study. This work was supported by an intramural grant from HKU, by the Li Ka Shing Foundation through the RESPARI project of the Institut Pasteur International Network and by the HKU-Biopharmaceutical Development Centre (to JMG, RB and RA); by Institut Pasteur, ANRS, Sidaction \& the EU (to OS). 


\section{References}

Baum, C., Schambach, A., Bohne, J., Galla, M. 2006. Retrovirus vectors: toward the plentivirus? Mol. Ther. 13, 1050-1063.

Bennasser, Y., Yeung, M.L., Jeang, K.T. 2007. RNAi therapy for HIV infection: principles and practicalities. BioDrugs 21, 17-22.

Bukreyev, A., Skiadopoulos, M.H., Murphy, B.R., Collins, P.L. 2006. Nonsegmented negative-strand viruses as vaccine vectors. J. Virol. 80, 10293-10306.

Burns, J.C., Friedmann, T., Driever, W., Burrascano, M., Yee, J.K. 1993. Vesicular stomatitis virus G glycoprotein pseudotyped retroviral vectors: Concentration to very high titer and efficient gene transfer into mammalian and nonmammalian cells. Proc. Natl. Acad. Sci. USA 90, 8033-8037.

Cao, Y.L., Guo, Y. 2008. Screening of HIV-1 replication inhibitors by using pseudotyped virus system. Yao Xue Xue Bao 43, 253-258.

Chan, E., Heilek-Snyder, G., Cammack, N., Sankuratri, S., Ji, C. 2006. Development of a Moloney murine leukemia virus-based pseudotype anti-HIV assay suitable for accurate and rapid evaluation of HIV entry inhibitors. J. Biomol. Screen. 11, 652-663.

Chan, S.Y., Empig, C.J., Welte, F.J., Speck, R.F., Schmaljohn, A., Kreisberg, J.F., Goldsmith, M.A. 2001. Folate receptor-alpha is a cofactor for cellular entry by Marburg and Ebola viruses. Cell 106, 117-126.

Clavel, F., Charneau, P. 1994. Fusion from without directed by human immunodeficiency virus particles. J. Virol. 68, 1179-1185.

Cohen J. 2007a. Did Merck's Failed HIV Vaccine Cause Harm? Science 318, 1048-1049.

Cohen J. 2007b. Promising AIDS vaccine's failure leaves field reeling. Science 318, 28-29.

Codran, A., Royer, C., Jaeck, D., Bastien-Valle, M., Baumert, T.F., Kieny, M.P., Pereira, C.A., Martin, J.P. 2006. Entry of hepatitis $C$ virus pseudotypes into primary human hepatocytes by clathrin-dependent endocytosis. J. Gen. Virol. 87, 2583-2593.

Connor, R.I. Chen, B.K., Choe, S., Landau, N. R. 1995. Vpr is required for efficient replication of human immunodeficiency virus type-1 in mononuclear phagocytes. Virology 206, 935-944.

De Clercq, E. 2000. Current lead natural products for the chemotherapy of human immunodeficiency virus (HIV) infection. Med. Res. Rev. 20, 323-349.

de la Carrière, L.C., Paulous, S., Clavel, F., Mammano, F. 1999. Effects of human immunodeficiency virus type 1 resistance to protease inhibitors on reverse transcriptase processing, activity, and drug sensitivity. J. Virol. 73, 3455-3459.

Esté, J.A., Telenti, A. 2007. HIV entry inhibitors. Lancet 370, 81-88.

Eustice, D.C., Feldman, P.A., Colberg-Poley, A.M., Buckery, R.M., Neubauer, R.H. 1991. A sensitive method for the detection of beta-galactosidase in transfected mammalian cells. Biotechniques 11 , 739-40 and 742-743. 
Faustino, R.S., Nelson, T.J., Terzic, A., Perez-Terzic, C. 2007. Nuclear transport: target for therapy. Clin. Pharmacol. Ther. 81, 880-886.

Flexner, C. 2007. HIV drug development: the next 25 years. Nat. Rev. Drug Discov. 6, 959-966.

Fukushi, S., Mizutani, T., Saijo, M., Kurane, I., Taguchi, F., Tashiro, M., Morikawa, S. 2006. Evaluation of a novel vesicular stomatitis virus pseudotype-based assay for detection of neutralizing antibody response to SARS-CoV. J. Med. Virol. 78, 1509-1512.

Goldgur, Y., Craigie, R., Cohen, G.H., Fujiwara, T., Yoshinaga, T., Fujishita, T., Sugimoto, H., Endo, T., Murai, H., Davies, D.R. 1999. Structure of the HIV-1 integrase catalytic domain complexed with an inhibitor: a platform for antiviral drug design. Proc. Natl. Acad. Sci. USA 96, 13040-13043.

Kim SH, Kim S, Robbins PD. 2000. Retroviral vectors. Adv. Virus Res. 55, 545-563.

Liu, Y., Murakami, N., Zhang, S., Xu, T. 2007. Structure-activity relationships of 1'-acetoxychavicol acetate homologues as new nuclear export signal inhibitors. Pharmazie 62, 659-662.

Lundholt, B.K., Scudder, K.M., Pagliaro, L. 2003. A simple technique for reducing edge effect in cell-based assays. J. Biomol. Screen. 8, 566-570.

Ma, M., Kersten, D.B., Kamrud, K.I., Wool-Lewis, R.J., Schmaljohn, C., Gonzalez-Scarano, F. 1999. Murine leukemia virus pseudotypes of La Cross and Hantaan bunyaviruses: a system for analysis of cell tropism. Virus Res. 64, 23-32.

Maréchal, V., Clavel, J.F., Heard, J.M., Schwartz, O. 1998. Cytosolic Gag p24 as an index of productive entry of human immunodeficiency virus type 1. J. Virol. 72, 2208-2212.

Mastromarino, P., Conti, C., Goldoni, P., Hauttecoeur, B., Orsi, N. 1987. Characterization of membrane components of the erythrocyte involved in vesicular stomatitis virus attachment and fusion at acidic pH. J. Gen. Virol. 68, 2359-2369.

Morizono, K., Harada, S. 1998. Human immunodeficiency virus type 1 (HIV-1) infection and transcytosis activity of a HIV-1 susceptible clone from HeLa cell. Microbiol. Immunol. 42, 313-320.

Moore, J.P., Kitchen, S.G., Pugach, P., Zack, J.A. 2004. The CCR5 and CXCR4 coreceptors-central to understanding the transmission and pathogenesis of human immunodeficiency virus type 1 infection. AIDS Res. Hum. Retroviruses 20, 111-126.

Mosmann, T. 1983. Rapid colorimetric assay for cellular growth and survival: application to proliferation and cytotoxicity assays. J. Immunol. Methods. 65, 55-63.

Muraglia, E., Kinzel, O.D., Laufer, R., Miller, M.D., Moyer, G., Munshi, V., Orvieto, F., Palumbi, M.C., Pescatore, G., Rowley, M., Williams, P.D., Summa, V. 2006. Tetrazole thioacetanilides: potent non-nucleoside inhibitors of WT HIV reverse transcriptase and its K103N mutant. Bioorg. Med. Chem. Lett. 16, 2748-2752.

Naldini, L., Blomer, U., Gallay, P., Ory, D., Mulligan, R., Gage, F.H., Verma, I.M., Trono, D. 1996. In vivo gene delivery and stable transduction of nondividing cells by a lentiviral vector. Science 272 , 263-267.

Nefkens, I., Garcia, J.M., Lagarde, N., Chu, K., Peiris, M., Buchy, P., Altmeyer, R. 2007. Hemagglutinin pseudotyped lentiviral particles: Characterization of a new tool for avian influenza H5N1 influenza serodiagnostic. J. Clin. Virol. 39, 27-33. 
Noah, J.W., Severson, W., Noah, D.L., Rasmussen, L., White, E.L., Jonsson, C.B. 2007. A cell based luminescence assay is effective for high-throughput screening of potential influenza antivirals.

Antiviral Res. 73, 50-59.

Olesen, C.E., Yan, Y.X., Liu, B., Martin, D., D'Eon, B., Judware, R., Martin, C., Voyta, J.C., Bronstein, I. 2000. Novel methods for chemiluminescent detection of reporter enzymes. Methods Enzymol. 326, 175-202.

Petit, C., Buseyne, F., Boccaccio, C., Abastado, J.P., Heard, J.M., Schwartz, O. 2001. Nef is required for efficient HIV-1 replication in cocultures of dendritic cells and lymphocytes. Virology 286, 225-236.

Pillay, D., Taylor, S., Richman, D.D. 2000. Incidence and impact of resistance against approved antiretroviral drugs. Rev. Med. Virol. 10, 231-253.

Ritz, C., Streibig, J.C. 2005. Bioassay Analysis using R.J. Statist. Software. Vol 12, Issue 5.

Salzwedel, K., Martin, D.E., Sakalian, M. 2007. Maturation inhibitors: a new therapeutic class targets the virus structure. AIDS Rev. 9, 162-172.

Schwartz O, Maréchal V, Danos O, Heard JM. 1995. Human immunodeficiency virus type 1 Nef increases the efficiency of reverse transcription in the infected cell. J. Virol. 69,4053-4059.

Sension, MG. 2007. Long-Term suppression of HIV infection: benefits and limitations of current treatment options. J. Assoc. Nurses AIDS Care 18, S2-10.

Sol-Foulon N, Sourisseau M, Porrot F, Thoulouze MI, Trouillet C, Nobile C, Blanchet F, di Bartolo V, Noraz N, Taylor N, Alcover A, Hivroz C, Schwartz O. 2007. ZAP-70 kinase regulates HIV cell-to-cell spread and virological synapse formation. EMBO J. 26, 516-526.

Soriano, V., de Mendoza, C. 2002. Genetic mechanisms of resistance to NRTI and NNRTI. HIV Clin. Trials 3, 237-248.

Sorin, M., Kalpana, G.V. 2006. Dynamics of virus-host interplay in HIV-1 replication. Curr. HIV Res. 4, $117-130$.

UNAIDS/WHO. 2007. AIDS Epidemic Update. December 2007. Geneva.

Watanabe, N., Yamaguchi, T., Akimoto, Y., Rattner, J.B., Hirano, H., Nakauchi, H. 2000. Induction of M-phase arrest and apoptosis after HIV-1 Vpr expression through uncoupling of nuclear and centrosomal cycle in HeLa cells. Exp. Cell Res. 258, 261-269.

Wool-Lewis, R.J., Bates, P. 1998. Characterization of Ebola virus entry by using pseudotyped viruses: identification of receptor deficient cell lines. J. Virol. 72, 3155-3160.

Yeni P. 2006. Update on HAART in HIV. J. Hepatol. 44, S100-103.

Zeinalipour-Loizidou, E., Nicolaou, C., Nicolaides, A., Kostrikis, L.G. 2007. HIV-1 integrase: from biology to chemotherapeutics. Curr. HIV Res. 5, 365-388.

Zhang, J.H., Chung, T.D., Oldenburg, K.R. 1999. A simple statistical parameter for use in evaluation and validation of high throughput screening assays. J. Biomol. Screen. 4, 67-73. 


\section{Figure legends}

Figure 1: Schematic representation of the orthogonal cocktail strategy. 100 "source plates" (depicted in grey) containing a single compound/well were laid out in a $10 \times 10$ grid. Orthogonal cocktails were made by mixing each compound of the same well (exemplified by the black dot shown in A1) for either the 10 plates of a row (red) or the 10 plates of a column (blue) into "cocktail plates". Each compound is represented twice in 20 mixture plates, each time with 9 different sister compounds.

Figure 2: Example of parameter optimization. The kinetic of infection was monitored at various cell densities and pseudoparticle ( $\mathrm{pp}$ ) dilutions as specified. Optimal results were achieved for all conditions between $48-72 \mathrm{~h}$ post-infection. Signal is expressed in Relative Luminescence Unit (RLU).

Figure 3: Example of primary screening output. 8000 compounds were screened in 10-compounds orthogonal cocktail plates. Horizontal lines correspond to different cut-off limits calculated from the average $(\mathrm{m})$ and standard deviation (SD) of samples. The activity of tested compounds was considered inhibitory when both values from $\mathrm{Y}$ (blue) and $\mathrm{X}$ (red) plates fell below the pre-defined cut-off (m-2SD). Control wells contained 0.1mM AZT (grey) or $2 \%$ DMSO (yellow) alone. Colored box shows the MTT cytotoxicity results subsequently obtained with the individual molecules: green: non toxic ( $<10 \%$ inhibition growth in MTT assay); orange: marginally toxic (between 10 to $30 \%$ inhibition growth), red: toxic (>50\% inhibition growth). Three of the compounds more thoroughly studied are identified by their library code name. Results are expressed in Relative Luminescence Unit (RLU).

Figure 4: Selectivity of inhibition. The specificity of post-entry inhibition of HIV was tested to exclude an effect of the VSV-G envelope (diamonds; cf. to HxB2, squares) or of the reporter gene luciferase (diamonds; cf. to GFP, triangles). As an 
additional control we found that the drug did not inhibit the replication of the Semliki Forest alphavirus (open circles). Other hits as well as AZT gave similar profiles (data not shown). The plot shows the percentage inhibition of the luciferase signal by compound NC83040 as a function of the drug concentration (expressed as the logarithm of molarity). Maximum (100\%) and minimum (0\%) values were recorded in the absence of pseudotyped particles and in the absence of the drug, respectively.

Figure 5: Time of addition study. Drugs were added at different time post infection. All drugs were ineffective when added $5 \mathrm{hrs}$ after infection with a time course similar to AZT.

Figure 6: Classification of the hits. All the hits can be derived from a general template; four major sub-families were identified from a detailed analysis of their chemical structures.

Figure 7: In silico docking. The model illustrates a portion of the crystal structure of reverse transcriptase in its bound conformation to the NNRTi Nevirapine (PDB 1FKP). All six drugs tested docked to the same binding pocket. Modelization realized with Argulab software.

Figure 8: Inhibition of live virus replication in cultured cells. Viral replication was monitored $72 \mathrm{hrs}$ post-infection (viral input $1 \mathrm{ng}$ ) by measuring ß-galactosidase activity in a colorimetric CPRG assay either in the presence or absence of drugs tested at three different concentrations: $5 \mu \mathrm{M}$ (white bars), $1 \mu \mathrm{M}$ (grey bars) and 0.1 $\mu \mathrm{M}$ (black bars). Six different strains of viruses were used: wild type NL4.3 (A); and different mutants resistant to the following drugs (B) AZT (NL4.3-XCS 41-215); (C) AZT, d4T, ddl (NL4.3-XCS MDR 151); (D) 3TC (NL4.3 XCS M184V); (E) NVP (NL4.3-XCS K103N) and (F) very resistant to NVP (NL 4.3 XCS 188L-190A). Percentage of inhibition was calculated from values obtained in wells infected in the 
absence of drugs (no drug), corrected for background noise (non infected cells, $\mathrm{NI}$ ). Results are shown as means \pm SD of three observations.

Table 1: Estimation of $\mathrm{IC}_{50}$ obtained by inhibition of live virus. Concentrations (nM) resulting in fifty percent inhibition of viral infection were derived for different strains of NL4.3 XCS (viral input $1 \mathrm{ng} \mathrm{p24,} \mathrm{MOI} \mathrm{0.02)} \mathrm{in} \mathrm{presence} \mathrm{of} \mathrm{increasing}$ drug concentrations (100 nM, $1 \mu \mathrm{M}$ and $5 \mu \mathrm{M}$ ). Values were estimated after fitting the inhibition data with the package "drc". ND: not determined; R: drug resistance (no inhibition of viral replication up to $5 \mu \mathrm{M}$ ). Results are shown as means \pm SD of six samples from two independent experiments (triplicate measurements).

Table 2: Estimation of $\mathrm{IC}_{50}$ obtained by inhibition of pseudoparticles. The concentrations $(\mathrm{nM})$ resulting in $50 \%$ inhibition of viral infection were calculated for the following different pseudotypes HIV-HxB2-HIV(Luc), VSV-G-HIV(Luc) and VSVG-HIV(GFP) (as mentioned in the Results, section 3.4). Values were fitted using the Hill equation and standard deviations were calculated from values obtained in quadruplicate from a single experiment.

\section{Supplementary Materials:}

Figure S1: Chemical structure of active and related inactive compounds belonging to the four chemical sub-families depicted in Figure 6.

Figure S2: Estimation of IC50 by sigmoid curve fitting. The plot illustrates, for the different strain of viruses, the dose-dependent inhibition of viral infection by AZT fitted using model L4 the freely downloadable package "drc" for "R" (see Materials and Methods). Experimental conditions were as in Figure 10. The response was measured as $\beta$-galactosidase activity in a CPRG colorimetric assay. Control values (no inhibition) correspond to the signal recorded in absence of drugs; the OD recorded in the absence of viruses is plotted as a $1 \mathrm{mM}$ drug concentration 
(corresponding to maximal inhibition).

Figure S3: Illustration of the potential complexity linked to the unambiguous identification of an active compound using the orthogonal cocktail strategy. In order to investigate which compound(s) was (were) responsible for the inhibitory effect, 9 compounds (corresponding to $3^{2}$ ) needed to be tested individually. In this case, only one molecule, NC85497, showed true inhibition, whereas 2 were toxic and the remaining 6 did not show any effect

Table S2: Estimation of $\mathrm{IC}_{50}$ obtained by inhibition of live virus (viral input: 5ng of p24). Concentrations (nM) resulting in fifty percent inhibition of viral infection were derived for different strains of NL4.3 XCS (viral input $5 \mathrm{ng} \mathrm{p24,} \mathrm{MOI} \sim 0.1$ ) in presence of increasing drug concentrations (100 $\mathrm{nM}, 1 \mu \mathrm{M}$ and $5 \mu \mathrm{M})$. Values were estimated after fitting the inhibition data with the package "drc". ND: not determined; T: cytotoxicity by cytopathic effect (CPE); R: drug resistance (no inhibition of viral replication up to $5 \mu \mathrm{M}$ ). Results are shown as means \pm SD of triplicate measurements. 
Figures at expected size for publication.

Figure 1:

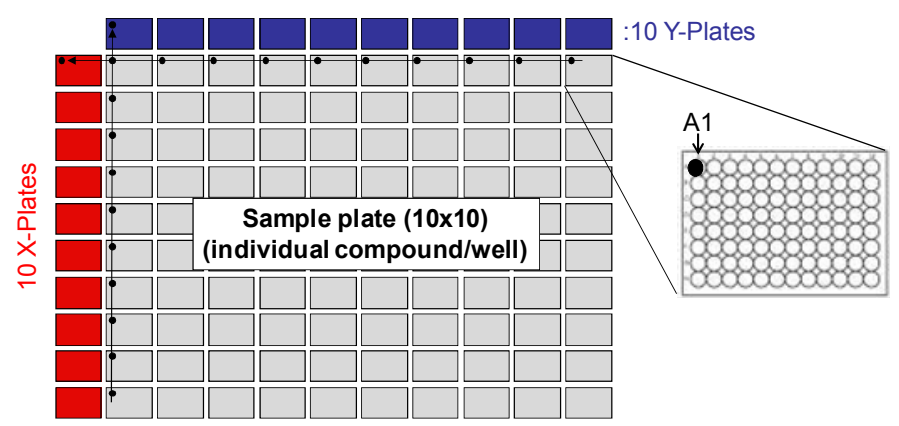

Figure 2:

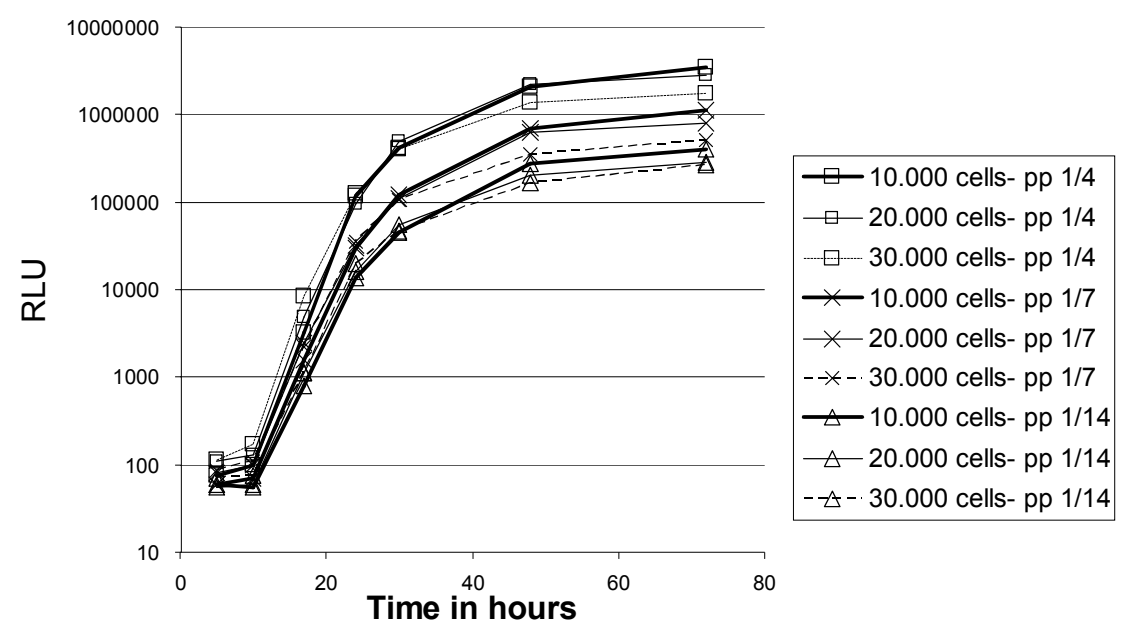

Figure 3:

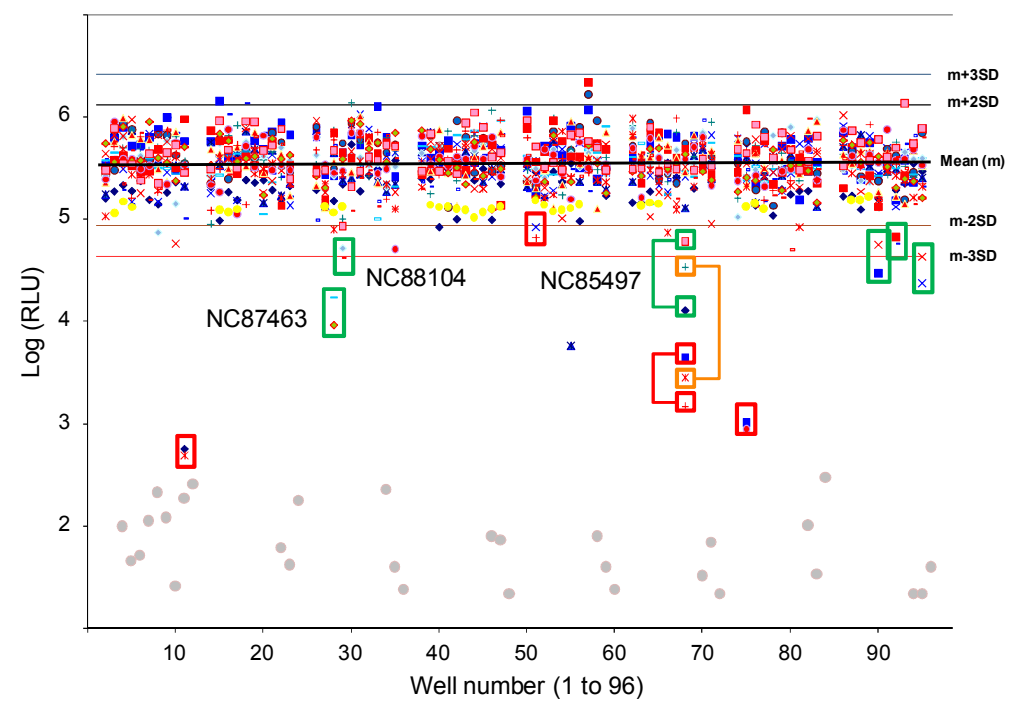


Figure 4:

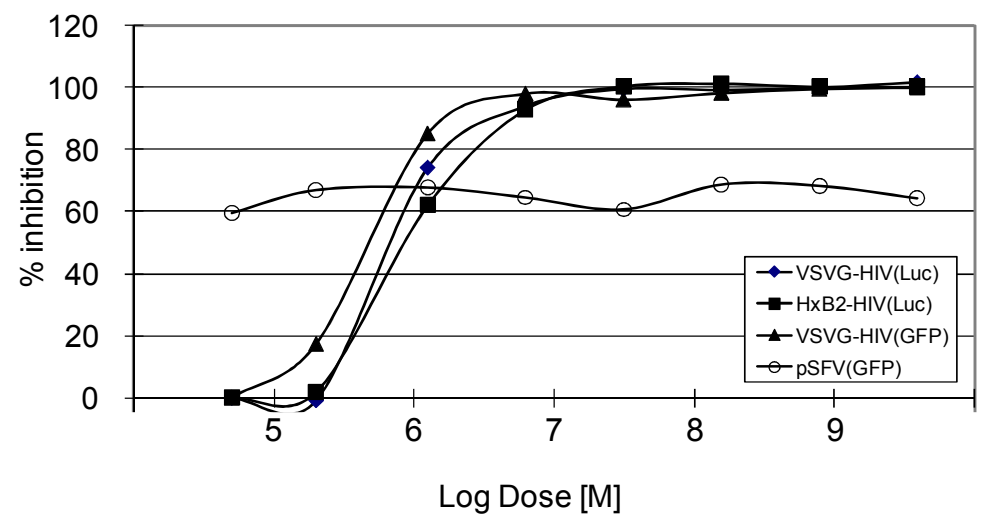

Figure 5:

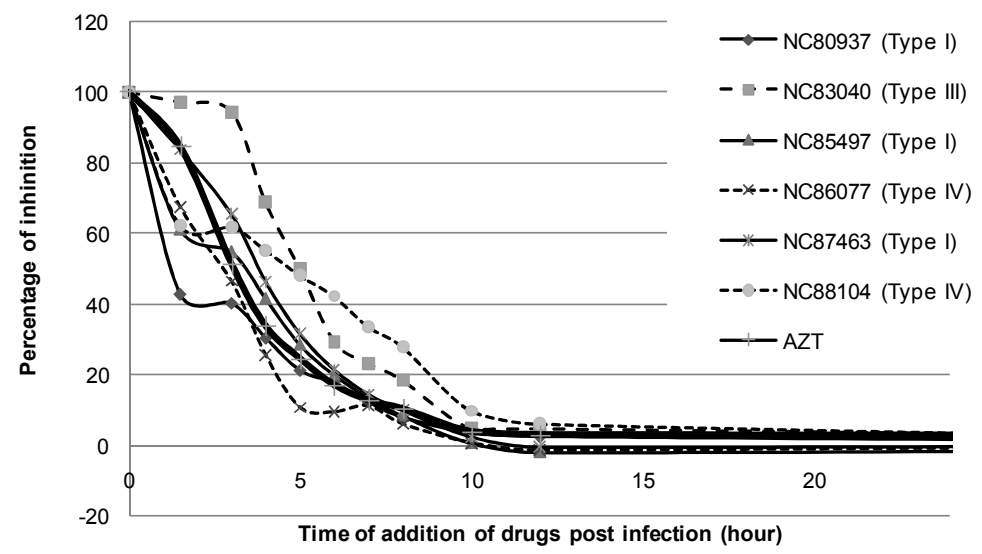

Figure 6:

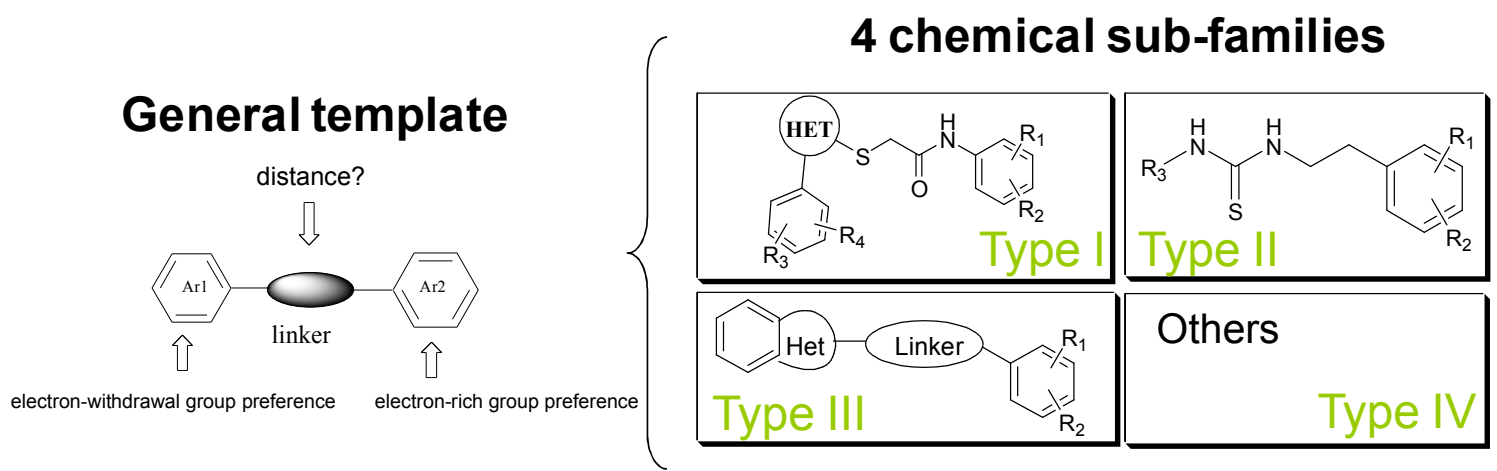


Figure 7:

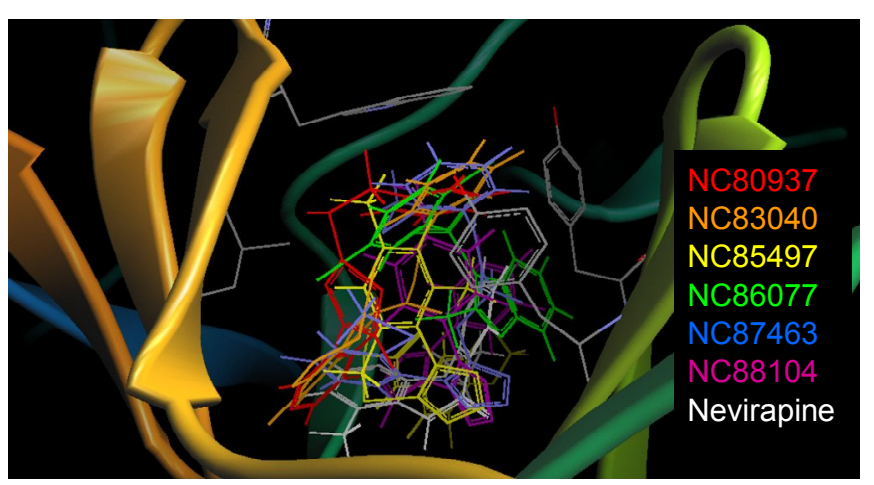

Figure 8: 

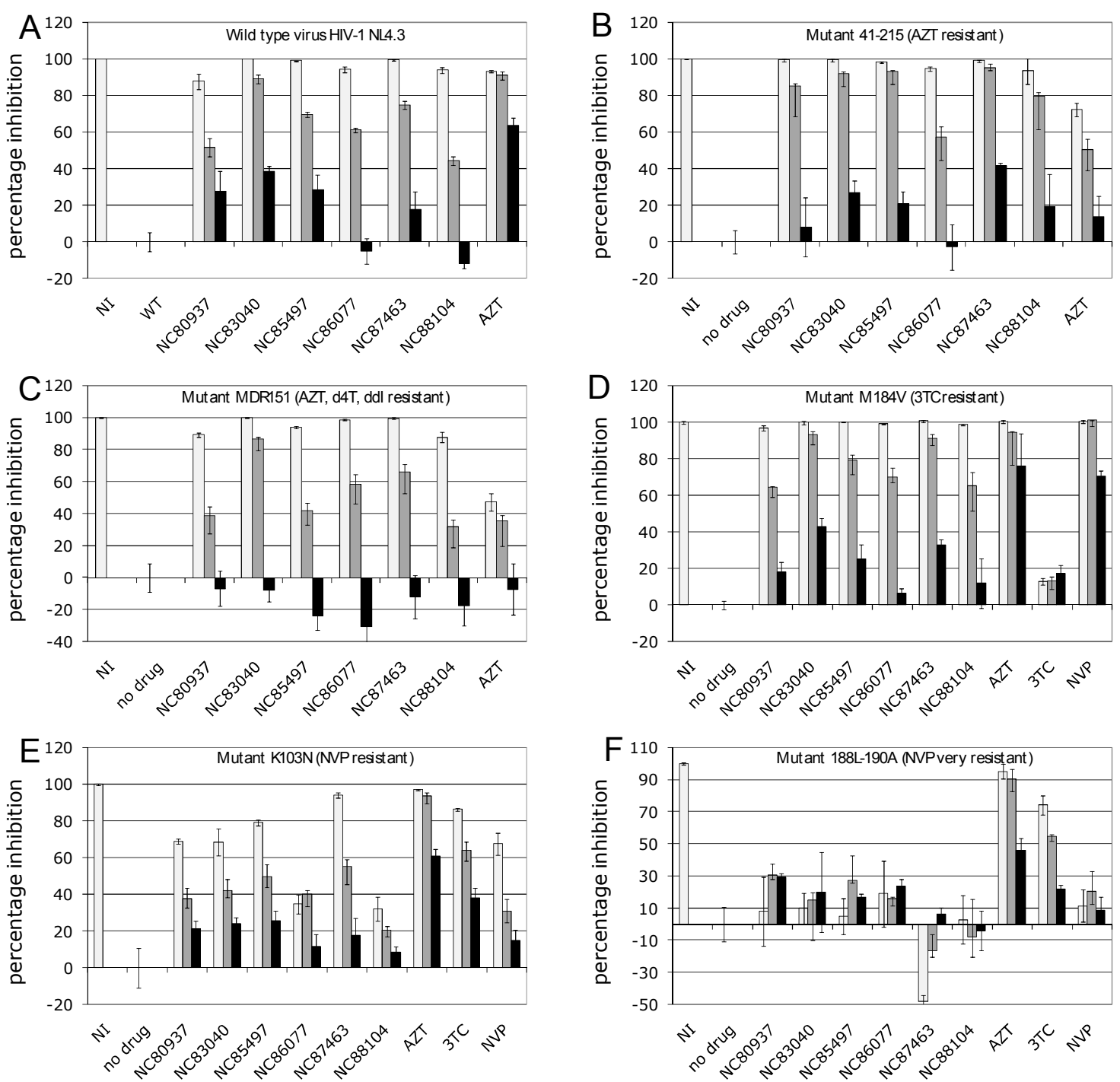

G

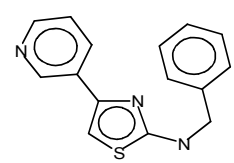

NC80937<smiles>C=C(Cc1ccccc1)[C@@]1(C)c2ccccc2CC[C@H]1C</smiles><smiles></smiles><smiles>Cc1cc(C)c(-c2ccc(CC(=O)Cc3ccc(I)c(O)c3)[nH]2)c(C)c1</smiles>

NC89497

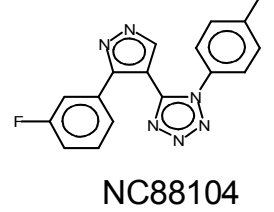




\section{Supplementary Material}

Figure S1:
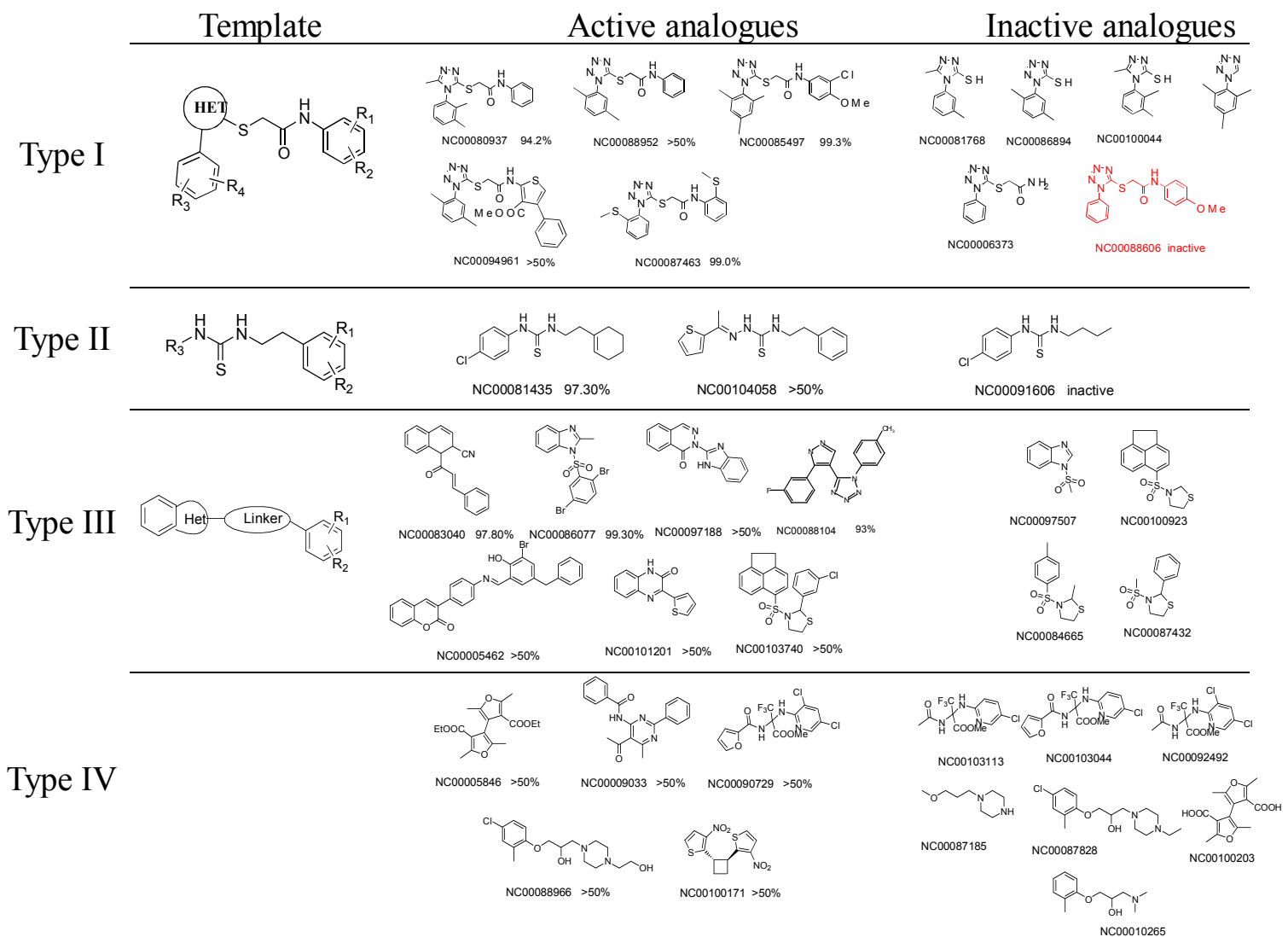

Figure S2:

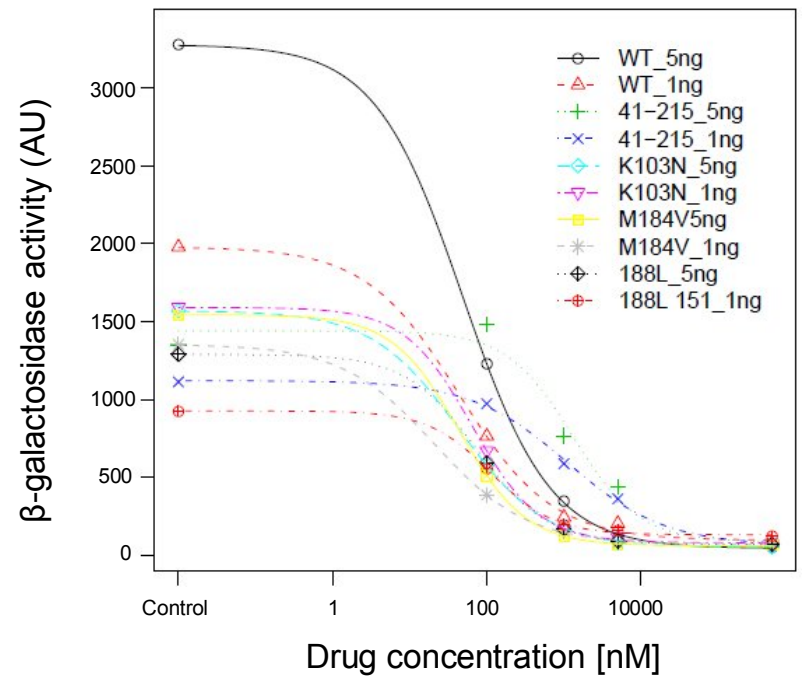

Figure S3: 


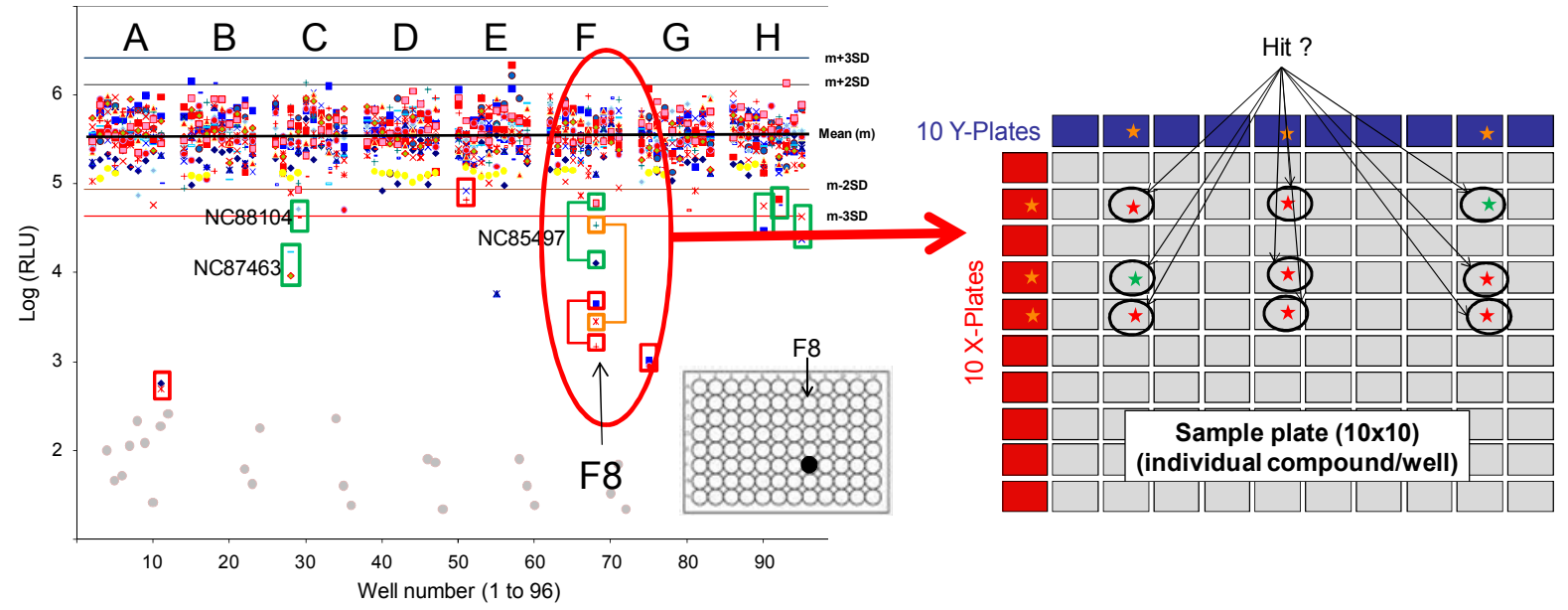


Table 1:

Virus strain (drug resistance)

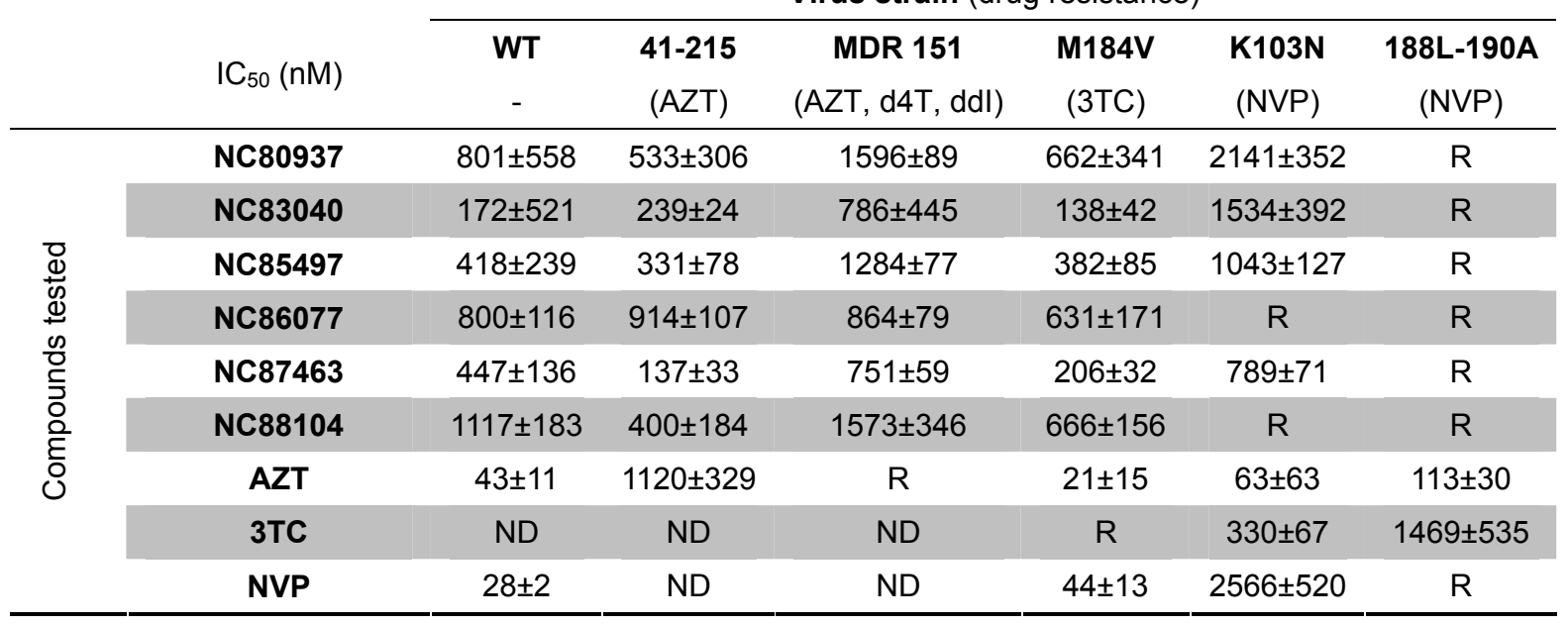

Table 2:

Pseudoparticle type

\begin{tabular}{|c|c|c|c|c|}
\hline & \multirow[b]{2}{*}{$\mathrm{IC}_{50}(\mathrm{nM})$} & \multirow{2}{*}{\multicolumn{2}{|c|}{ HxB2-HIV(Luc) }} & \multirow{2}{*}{ VSV-G-HIV(GFP) } \\
\hline & & & & \\
\hline \multirow{7}{*}{ 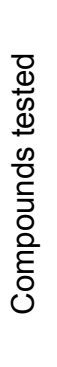 } & NC80937 & $201 \pm 64$ & $274 \pm 87$ & $584 \pm 126$ \\
\hline & NC83040 & $105 \pm 7$ & $141 \pm 24$ & $280 \pm 16$ \\
\hline & NC85497 & $119 \pm 44$ & $299 \pm 52$ & $758 \pm 16$ \\
\hline & NC86077 & $202 \pm 54$ & $289 \pm 66$ & $1130 \pm 151$ \\
\hline & NC87463 & $92 \pm 7$ & $83 \pm 46$ & $183 \pm 45$ \\
\hline & NC88104 & $207 \pm 15$ & $263 \pm 126$ & $730 \pm 131$ \\
\hline & AZT & $3 \pm 0.5$ & $4 \pm 1$ & $1.3 \pm 0.1$ \\
\hline
\end{tabular}

Table S1

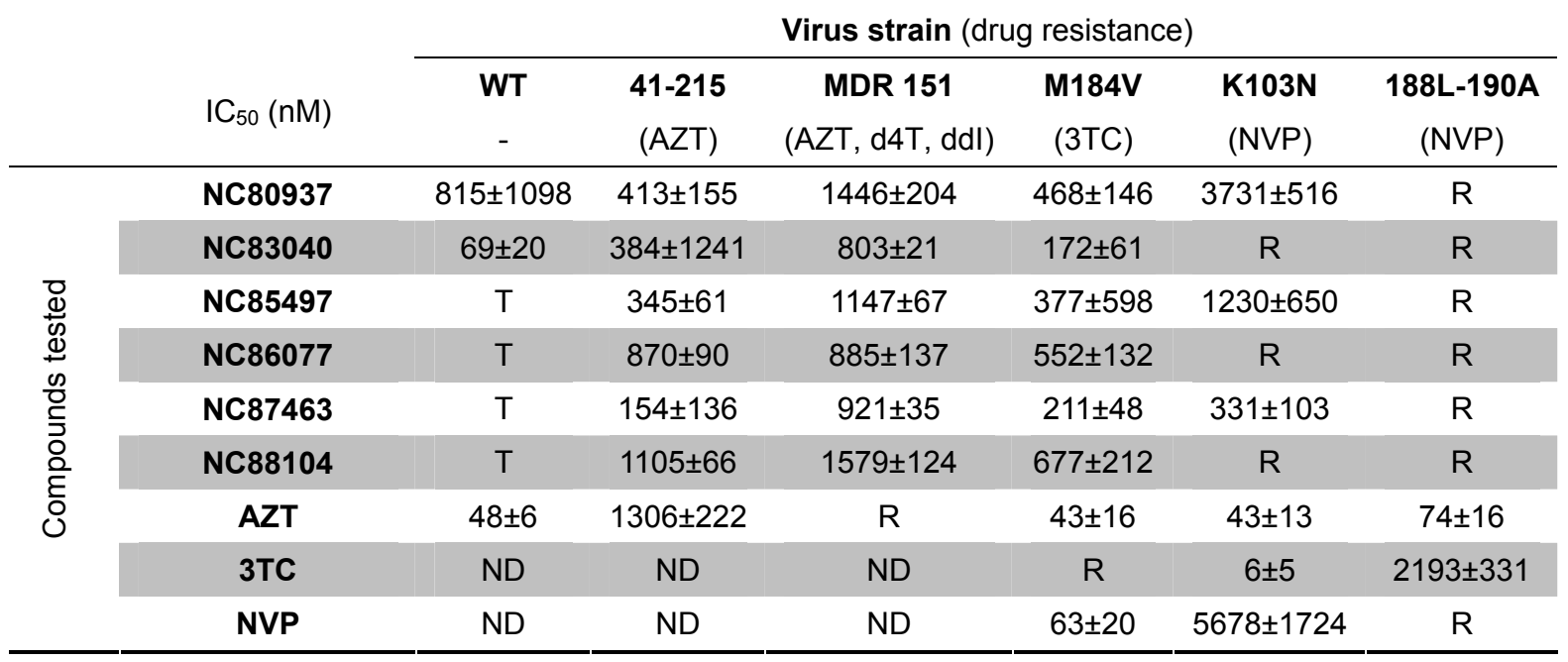

